\title{
Closed-Loop Polymer Upcycling by Installing Property-Enhancing Comonomer Sequences and Recyclability
}

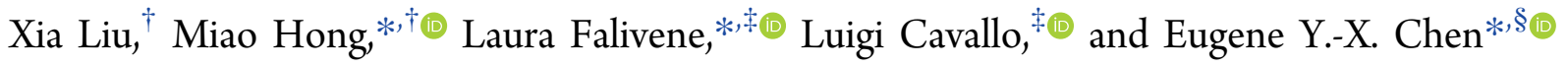 \\ ${ }^{\dagger}$ State Key Laboratory of Organometallic Chemistry, Shanghai Institute of Organic Chemistry, Chinese Academy of Sciences, \\ Shanghai 200032, P. R. China \\ ${ }^{\ddagger}$ Physical Sciences and Engineering Division, Kaust Catalysis Center, King Abdullah University of Science and Technology \\ (KAUST), Thuwal 23955-6900, Saudi Arabia \\ ${ }^{\S}$ Department of Chemistry, Colorado State University, Fort Collins, Colorado 80523-1872, United States
}

Supporting Information

ABSTRACT: The concept of upcycling postconsumer plastics into higher-value products is attractive, but the challenges remain to develop a cost-effective upcycling scheme, discover propertyenhancing structures, and, most importantly, install recyclability into upcycled plastics to enable a circular lifecycle. Reported herein is a convenient and effective strategy to upcycle polyester, exemplified by poly(glycolic acid) (PGA), via transesterification (TEster) in bioderived, commercially available $\gamma$-butyrolactone (BL) that serves as both the solvent and comonomer, which generates sequence-defined copolymer poly(GA-co-BL). Owing to the isolated glycolic sequence present in the copolymer created uniquely by TEster, it exhibits much-enhanced thermal stability $\left(\geq 44{ }^{\circ} \mathrm{C}\right)$ over both homopolymers or copolymers without such sequences. This upconverted copolymer is chemically recyclable, enabling a complete recovery of pure glycolic acid and BL feedstocks.

\section{INTRODUCTION}

Current methods for recycling of postconsumer plastics are largely ineffective due to minimally retained material's values, thus presenting a pressing need and also an innovation opportunity for developing new approaches to recycle plastics more effectively, en route to an end goal of achieving a circular materials economy. ${ }^{1-21}$ In this context, the concept of upcycling is an attractive approach, as, in principle, highervalue or value-added new materials would be the end products of the upcycling or repurposing process. ${ }^{22-30}$ However, the challenges have been either the need to use expensive reagents or fine chemicals and/or elaborated conditions for the upconversion or postmodification of the existing polymers into the higher-value products or the generation of new materials waste when the upcycled polymers are no more recyclable than the previous polymers. ${ }^{22-30}$

Copolymerizing two or more monomers is a well-established strategy to create new copolymer materials that often deliver unattainable or improved properties over those of homopolymers. $^{31-34}$ By adjusting the comonomer chemical nature, sequence, stereochemistry, and the composition, the properties and functions of the resultant copolymers can be tailored in a wide range to meet the desired application demand. ${ }^{35-45} \mathrm{~A}$ notable example in this context is poly(lactide-co-glycolide) (PLGA), ${ }^{46-54}$ which was approved by FDA for biomedical applications and shows improved flexibility, processability, and degradation behavior, relative to homopolymer poly(glycolic

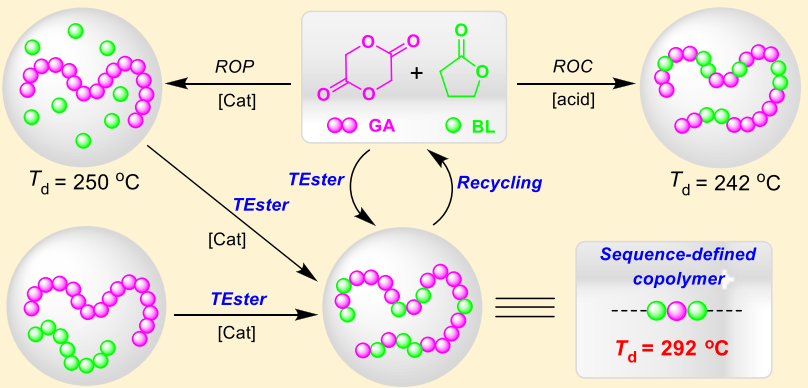

acid) (PGA), since PGA's melting-transition temperature $\left(T_{\mathrm{m}}\right)$ of $\sim 219{ }^{\circ} \mathrm{C}$ is close to its onset thermal decomposition temperature $\left(T_{\mathrm{d}}\right)$ of $\sim 250{ }^{\circ} \mathrm{C}$, and its dissolvability in common organic solvents is extremely poor. ${ }^{46,47}$ Nevertheless, the resulting PLGA is still a rather brittle material $(\sim 6 \%$ elongation at break).

By exploiting the unique ability of the copolymerization to create new or better materials, we reasoned that plastic upcycling could be achieved through the formation of betterperforming copolymers that incorporate property-enhancing functions or structures into the resulting copolymer. However, to realize a closed-loop upcycling scheme, three challenges must be addressed: (a) to develop a synthetic pathway that can produce such copolymers in a convenient and cost-effective manner; (b) to uncover property-enhancing copolymer structures or functions; and (c) to install the recyclability into the upcycled copolymers. Here, we present a proof-ofconcept example to demonstrate the feasibility of such an upcycling strategy. In this example of upcycling of polyester, represented by PGA, it was simply treated with bioderived $\gamma$ butyrolactone (BL) as both solvent and comonomer to produce sequence-defined copolymer poly (GA-co-BL) with $\mathrm{BL}$ incorporation up to $20.0 \%$ (the percent $\mathrm{BL}$ relative to the

Received: April 20, 2019

Revised: May 19, 2019

Published: June 12, 2019 
Scheme 1. Proposed TEster Pathways to Produce Poly(GA-co-BL) with Various Possible Sequences $($ G $=1 / 2$ GA, B = BL RingOpened Unit) Starting from Homopolymer PGA and Comonomer BL, where $k_{\mathrm{GG}}$ Defines the Rate Constant for the G-

Centered Anion-Attacking G-Chain Carbonyl, whereas $k_{\mathrm{GB}}$ and $k_{\mathrm{GB}^{\prime}}$ Represent the Rate Constant for the G-Centered AnionAttaching B (BL) Monomer and B' (B Chain Carbonyl), Respectively ${ }^{a}$

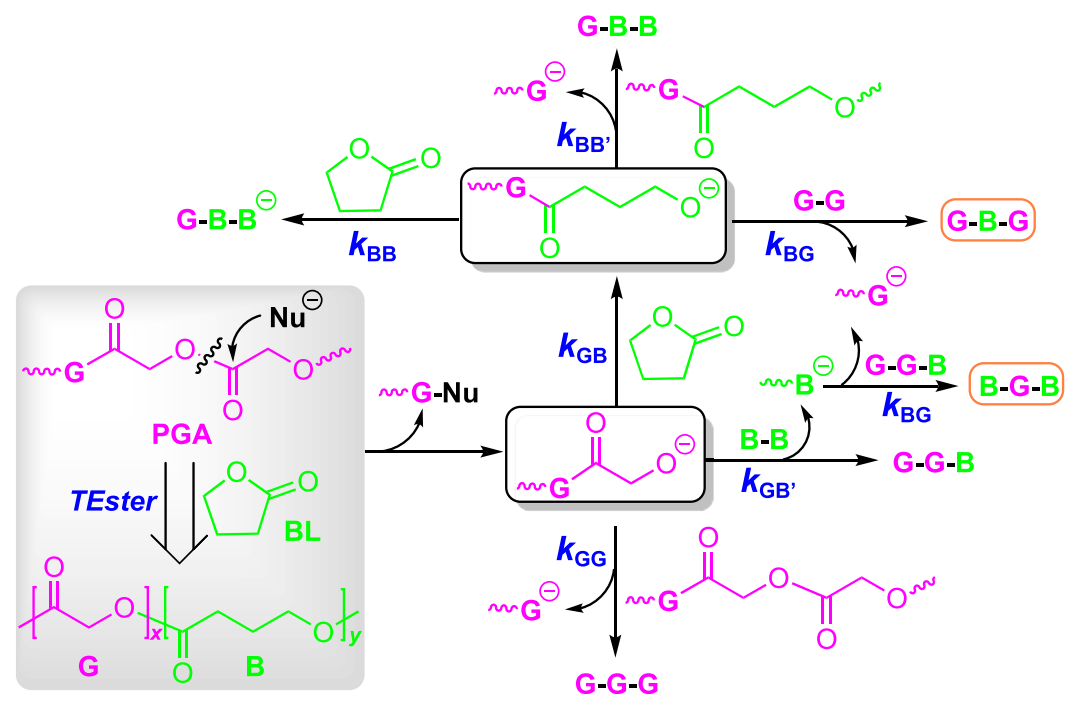

${ }^{a}$ Likewise, $k_{\mathrm{BB}}, k_{\mathrm{BB}}$, and $k_{\mathrm{BG}}$ are defined similarly.

Table 1. Results of the TEster between PGA and $\mathrm{BL}^{a}$

\begin{tabular}{|c|c|c|c|c|c|c|c|c|c|c|}
\hline run & cat. & I. & temp $\left({ }^{\circ} \mathrm{C}\right)$ & solvent & time (day) & yield $^{b}(\mathrm{mg})$ & incorp. $^{c}(\mathrm{BL} \%)$ & $M_{\mathrm{n} \mathrm{NMR.}}{ }^{d}(\mathrm{~kg} / \mathrm{mol})$ & $M_{\mathrm{n} \mathrm{GPC.}}{ }^{e}(\mathrm{~kg} / \mathrm{mol})$ & $\bigoplus^{e} M_{\mathrm{w}} / M_{\mathrm{n}}$ \\
\hline 1 & $\mathrm{La}$ & $\mathrm{BnOH}$ & 25 & THF & 7 & 95 & 5.00 & 3.70 & & \\
\hline 2 & $\mathrm{La}$ & & 25 & THF & 7 & 98 & 1.00 & $f$ & & \\
\hline 3 & TBD & & 25 & DCM & 7 & 96 & 2.70 & $f$ & & \\
\hline 4 & TBD & $\mathrm{BnOH}$ & 25 & DCM & 7 & 95 & 3.23 & 4.04 & & \\
\hline 5 & DBU & & 25 & DCM & 7 & 97 & 1.41 & $f$ & & \\
\hline 6 & DBU & $\mathrm{BnOH}$ & 25 & DCM & 7 & 96 & 2.86 & 4.27 & & \\
\hline 7 & ${ }^{t} \mathrm{Bu}-\mathrm{P}_{4}$ & & 25 & THF & 7 & 99 & 0.61 & $f$ & & \\
\hline 8 & ${ }^{t} \mathrm{Bu}-\mathrm{P}_{4}$ & $\mathrm{BnOH}$ & 25 & THF & 7 & 96 & 2.43 & 4.28 & & \\
\hline 9 & $\mathrm{La}$ & $\mathrm{BnOH}$ & 25 & $\mathrm{BL}$ & 7 & 98 & 5.43 & 3.85 & & \\
\hline 10 & $\mathrm{La}$ & $\mathrm{BnOH}$ & 80 & $\mathrm{BL}$ & 1 & 96 & 2.83 & 10.6 & & \\
\hline 11 & $\mathrm{La}$ & $\mathrm{BnOH}$ & 120 & $\mathrm{BL}$ & 1 & 100 & 8.34 & 6.20 & & \\
\hline 12 & $\mathrm{La}$ & $\mathrm{BnOH}$ & 160 & $\mathrm{BL}$ & 1 & 103 & 14.3 & 6.50 & 6.38 & 1.25 \\
\hline 13 & $\mathrm{La}$ & $\mathrm{BnOH}$ & 160 & $\mathrm{BL}$ & 0.5 & 99 & 11.7 & 5.70 & 4.68 & 1.19 \\
\hline 14 & $\mathrm{La}$ & $\mathrm{BnOH}$ & 160 & $\mathrm{BL}$ & 1.5 & 105 & 18.6 & 6.60 & 6.51 & 1.22 \\
\hline 15 & $\mathrm{La}$ & $\mathrm{BnOH}$ & 160 & $\mathrm{BL}$ & 2 & 107 & 20.0 & 6.80 & 6.61 & 1.25 \\
\hline 16 & TBD & $\mathrm{BnOH}$ & 160 & $\mathrm{BL}$ & $1 \mathrm{~h}$ & 100 & 7.00 & 8.58 & & \\
\hline 17 & TBD & $\mathrm{BnOH}$ & 160 & $\mathrm{BL}$ & $4 \mathrm{~h}$ & 102 & 16.8 & 7.60 & 7.25 & 1.20 \\
\hline 18 & TBD & $\mathrm{BnOH}$ & 160 & $\mathrm{BL}$ & $6 \mathrm{~h}$ & 106 & 17.2 & 4.23 & 6.50 & 1.15 \\
\hline 19 & $\mathrm{La}$ & $\mathrm{BnOH}$ & 160 & $\mathrm{BL}$ & 2 & 104 & 19.3 & 6.92 & 6.80 & 1.30 \\
\hline
\end{tabular}

${ }^{a}$ Conditions for runs $1-8:$ cat. $=51.6 \mu \mathrm{mol}, \mathrm{PGA}=100 \mathrm{mg}, \mathrm{BL}=390 \mathrm{mg},[\mathrm{BL}+\mathrm{PGA}] / \mathrm{cat} . / \mathrm{I} .=100 / 1 / 2, \mathrm{BL} / \mathrm{PGA}=5$, solvent $=0.5 \mathrm{~mL}$; conditions for runs 9-18: cat. $=5.16 \mu \mathrm{mol}, \mathrm{BnOH}=10.32 \mu \mathrm{mol}, \mathrm{PGA}=100 \mathrm{mg}, \mathrm{BL}=1.0 \mathrm{~mL}$; conditions for run $19:$ cat. $=5.16 \mu \mathrm{mol}, \mathrm{BnOH}=$ $10.32 \mu \mathrm{mol}, \mathrm{PGA}=100 \mathrm{mg}, \mathrm{PBL}=113 \mathrm{mg}, \mathrm{BL}=0.9 \mathrm{~mL} .{ }^{b}$ Isolated yield. ${ }^{c} \mathrm{BL}$ incorporation of the copolymer was measured by ${ }^{1} \mathrm{H}$ NMR spectrum $\left(\mathrm{BL} \mathrm{mol} \mathrm{\%}=\left[I_{\mathrm{B}} /\left(I_{\mathrm{B}}+I_{\mathrm{G}}\right)\right] \times 100 \%=\left[I_{2.14 \mathrm{ppm}} /\left(I_{2.14 \mathrm{ppm}}+I_{4.92-5.02 \mathrm{ppm}}\right)\right] \times 100 \%, \mathrm{G}=\right.$ glycolyl $\left.\left(-\mathrm{COCH}_{2} \mathrm{O}-\right)\right) .{ }^{d}$ Calculated by ${ }^{1} \mathrm{H}$ NMR spectra: $M_{\mathrm{n}}(\mathrm{g} / \mathrm{mol})=\left(58.03 \times I_{4.92-5.02 \mathrm{ppm}}+86.09 \times I_{2.14 \mathrm{ppm}}\right) / I_{5.31 \mathrm{ppm}}+108.13(\mathrm{BnOH}) .{ }^{e} M_{\mathrm{n}}$ and $Ð$ were determined by $\mathrm{GPC}$ at $40{ }^{\circ} \mathrm{C}$ in $\mathrm{DMF} / \mathrm{LiBr}$ relative to poly (methyl methacrylate) standards. ${ }^{f}$ The signals of chain-end groups were difficult to detect in ${ }^{1} \mathrm{H}$ NMR spectrum.

glycolyl $\left(\mathrm{COCH}_{2} \mathrm{O}\right)$ unit, abbreviated as $\mathrm{G}$, which is $1 / 2$ glycolide) via catalyzed transesterification (TEster). Interestingly, this copolymer exhibits much-enhanced thermal stability $\left(\geq 44{ }^{\circ} \mathrm{C}\right.$ ) over both homopolymers (PGA and PBL) or copolymers without such sequences, thanks to the presence of isolated $G$ sequences $[G-B-G$ or $B-G-B ; B=B L$ ringopened unit] unique to the copolymer produced by TEster. Also importantly, this upcycled poly(GA-co-BL) can be completely recycled back to its building blocks, glycolic acid and BL, thus successfully constructing a closed-loop upcycling scheme.

\section{RESULTS AND DISCUSSION}

Upconversion of PGA to Copolymer by TEster. The choice of $\mathrm{BL}$ as both the comonomer and solvent for upcycling of PGA was primarily based on two reasons. First, it is a bioderived monomer or industrial solvent, readily available in large quantities, ${ }^{55}$ and its good solubility for many chemicals 
and polymers could potentially dissolve long crystalline GA blocks to ensure the formation of copolymers with a homogeneous composition. Second, it has been established that $\mathrm{PBL}$, synthesized via ring-opening polymerization of nonstrained BL under suitable thermodynamic, kinetic, and processing conditions with metal-based or organic catalysts, ${ }^{15,16,56-60}$ can be selectively and quantitatively recycled back to BL by thermolysis or chemolysis. ${ }^{15,16}$ Therefore, the utilization of $\mathrm{BL}$ may enable or enhance the chemical recyclability of the upcycled copolymer.

At the outset, we needed to synthesize the target poly(GAco-BL) copolymer to examine its properties and chemical recyclability and in turn answer the question of whether this material constitutes an upcycled product or not. Direct ringopening copolymerization (ROC) of highly reactive GA with highly stable BL was reported to be successful only by cationic polymerization with acidic initiators, producing copolymers in low yields (e.g., $1.4 \%$ by $\mathrm{FeCl}_{3}$ after $44 \mathrm{~h}$ at $60{ }^{\circ} \mathrm{C}$; $26 \%$ by $\mathrm{Sn}(\mathrm{Ph})_{4}$ after $96 \mathrm{~h}$ at $\left.140{ }^{\circ} \mathrm{C}\right) .{ }^{61,62}$ Metal-mediated or organicmediated anionic ROC of $\mathrm{BL}$ with moderately reactive lactones such as $\varepsilon$-caprolactone was successful. ${ }^{63,64}$ Consistent with the very large reactivity difference between GA and $\mathrm{BL}$ toward ROC, our attempted synthesis of poly(GA-co-BL) via ROC of GA and $\mathrm{BL}$ by either coordination or anionic polymerization with metal-based $\mathrm{La}\left[\mathrm{N}\left(\mathrm{SiMe}_{3}\right)_{2}\right]_{3}$ (with or without $\mathrm{BnOH})$ and organic phosphazene superbase ${ }^{t} \mathrm{Bu}-\mathrm{P}_{4} /$ $\mathrm{BnOH}$ catalyst/initiator systems was unsuccessful, producing exclusively PGA homopolymer with no BL incorporation, even with excess $\mathrm{BL}(\mathrm{BL} / \mathrm{GA}=10 / 1)$ and at low temperature $(-40$ ${ }^{\circ} \mathrm{C}$, the condition suitable for facile ROP of BL) (Figure S1). The use of other metal catalysts such as the discrete yttrium complex supported by the amino-alkoxy-bisphenolate ligand ${ }^{65}$ as well as other commonly used organic catalysts [e.g., 1,5,7triazabicyclo[4.4.0] dec-5-ene (TBD), 1,8-diazabicyclo[5.4.0]undec-7-ene (DBU) $]^{66-68}$ gave the same result. By employing the strategy developed for the synthesis of random PLGA, ${ }^{54}$ the copolymerization was also performed by slow and continuous addition of a GA solution to $\mathrm{BL}$ after initiating $\mathrm{BL}$ first; however, the resulting product turned out to be the mixture of PGA and $\mathrm{PBL}$, rather than the anticipated copolymer (Figures S2 and S3). The use of $\mathrm{BnOH}$ as the initiator in the cationic copolymerization promoted by $\mathrm{BF}_{3}$. $\mathrm{Et}_{2} \mathrm{O}$ and $\mathrm{CF}_{3} \mathrm{SO}_{3} \mathrm{H}$ can improve the yield and $\mathrm{BL}$ incorporation (up to $33.8 \%$, Table S1 and Figure S4), but the resulting copolymer is an inferior material with a noticeably lower $T_{\mathrm{d}}\left(241{ }^{\circ} \mathrm{C}\right)$ than PGA.

The above largely unsuccessful attempts pointed to a need to develop a new synthetic pathway by employing homopolymer PGA directly. In this context, we reasoned that the TEster between PGA and BL with a suitable catalyst could afford the copolymer according to the pathways outlined in Scheme 1. The TEster between PGA and BL was examined with different catalysts and solvents at $25{ }^{\circ} \mathrm{C}$ (runs $1-8$, Table $1)$, successfully affording poly (GA-co-BL) with $\mathrm{BL}$ incorporations up to $5.0 \%$ by the best-performing catalyst/initiator $\mathrm{La}\left[\mathrm{N}\left(\mathrm{SiMe}_{3}\right)_{2}\right]_{3} / \mathrm{BnOH}$ in tetrahydrofuran (THF) (run 1, Table 1), albeit for a long time (7 days). Next, we performed the TEster of PGA in BL that serves as both the solvent and comonomer at different temperatures, rendering the efficient synthesis of poly(GA-co-BL) with BL incorporations ranging from 2.83 to $20.0 \%$ while reducing the reaction time to $12 \mathrm{~h}$ when performed at $160{ }^{\circ} \mathrm{C}$ (runs 9-15, Table 1). The TEster by $\mathrm{TBD} / \mathrm{BnOH}$ was even faster (runs 16-18, Table 1), producing poly (GA-co-BL) with a high $\mathrm{BL}$ incorporation up to $17.2 \%$ in $6 \mathrm{~h}$. The resultant copolymers with BL incorporations above $12.0 \%$ all exhibit good dissolvability in dimethylformamide (DMF), which enabled measurements of molecular weights by gel-permeation chromatography (GPC), showing a somewhat heterogeneous composition of the copolymer at the early stage of the TEster and then gradually becoming homogeneous at the late stages (Figure S5), as indicated by unimodal distribution with relatively low dispersity (e.g., $M_{\mathrm{n}}=$ $6.61 \mathrm{~kg} / \mathrm{mol}, Ð=1.25$ for the copolymer with $20.0 \% \mathrm{BL}$ incorporation). However, for the copolymers with low $\mathrm{BL}$ incorporations $(<12 \%)$, the dissolvability in common organic solvents (e.g., DMF, THF, $\mathrm{CHCl}_{3}, \mathrm{CH}_{2} \mathrm{Cl}_{2}$ ) is extremely poor. Corrosive fluorinated solvents (e.g., trifluoroacetic acid) are required to dissolve these copolymers. Even in hexafluoroisopropanol, such copolymers are only partially soluble. Hence, the poor dissolvability of these copolymers makes GPC measurements infeasible. Noteworthy, here the TEster between two homopolymers PGA and PBL by La[N$\left.\left(\mathrm{SiMe}_{3}\right)_{2}\right]_{3} / \mathrm{BnOH}$ was also successful; monitoring the reaction by ${ }^{1} \mathrm{H}$ NMR showed that it started with fast, quantitative depolymerization of $\mathrm{PBL}$ into $\mathrm{BL}$, followed by the TEster between PGA and BL in which the activity and BL incorporation (run 19, Table 1) were similar to the TEster starting with PGA and BL. To determine if the copolymer by the cationic ROC of GA and $\mathrm{BL}$ with $\mathrm{BF}_{3} \cdot \mathrm{Et}_{2} \mathrm{O} / \mathrm{BnOH}$ was also produced by the TEster mechanism, we performed the kinetic study. Specifically, extending the polymerization time from 2 to $12 \mathrm{~h}$, the copolymer yield increased from 16.0 to $43.6 \%$, while the BL incorporation was maintained at around $20 \%$ (runs 5, 8-10, Table S1), indicating the copolymer by cationic polymerization was not obtained by the TEster pathway.

Property-Enhancing Comonomer Sequences. ${ }^{1} \mathrm{H}$ and ${ }^{13} \mathrm{C}$ NMR analyses of the selected poly(GA-co-BL) samples showed different copolymer microstructures produced by the TEster with $\mathrm{La}\left[\mathrm{N}\left(\mathrm{SiMe}_{3}\right)_{2}\right]_{3} / \mathrm{BnOH}$ from those by cationic ROC with $\mathrm{BF}_{3} \cdot \mathrm{Et}_{2} \mathrm{O} / \mathrm{BnOH}^{61,62}$ Because the chemical shifts of the glycolyl unit $(\mathrm{G})$ and $\mathrm{BL}$ ring-opened unit (B) are sensitive to electronic differences, the detailed sequence information of triad glycolyl units and dyad BL ring-opened units can be revealed by ${ }^{1} \mathrm{H}$ NMR. Thus, for the copolymers formed by TEster, the peaks at $\delta 5.02,4.92-4.95$, and 4.86 ppm (Figure $1 \mathrm{~b}, \mathrm{c}$ ) are attributed to the $\mathrm{CH}_{2}$ protons of the glycolyl unit with a $\mathrm{G}-\mathrm{G}-\mathrm{G}$ homosequence, $\mathrm{B}-\mathrm{G}-\mathrm{G} / \mathrm{G}-\mathrm{G}-$ $B$ heterosequence, and $B-G-B$ alternating sequence, respectively. The signals of the $\mathrm{CH}_{2}$ protons of the $\mathrm{BL}$ ringopened unit split into two sets of peaks, in which the predominant peaks at $\delta 4.40,2.72$, and $2.17 \mathrm{ppm}$ correspond to $\mathrm{B}-\mathrm{G}$ alternating sequence while minor peaks at $\delta 4.32,2.61$, and $2.11 \mathrm{ppm}$ are attributed to the $\mathrm{B}-\mathrm{B}$ homosequence.

Table 2 lists the calculated molar fractions of different sequences based on ${ }^{1} \mathrm{H}$ NMR spectra. With increasing $\mathrm{BL}$ incorporation in the copolymer produced by the TEster with $\mathrm{La}\left[\mathrm{N}\left(\mathrm{SiMe}_{3}\right)_{2}\right]_{3} / \mathrm{BnOH}$ from 5.00 to $20.0 \%$, the molar fraction of the $\mathrm{G}-\mathrm{G}-\mathrm{G}$ homosequence decreased from 93.5 to $60.8 \%$, while that of the isolated $G$ in the form of $B-G-B$ alternating sequence enhanced from 0.65 to $4.50 \%$. In contrast, the content of the B-B homosequence was kept at the constantly low level of $\sim 7.0 \%$, independent of the $\mathrm{BL}$ incorporation (entries 1-4, Table 2). The copolymer obtained by the TEster with $\mathrm{TBD} / \mathrm{BnOH}$ had similar sequence distributions (entry 5, Table 2). However, the microstructure of the copolymer 


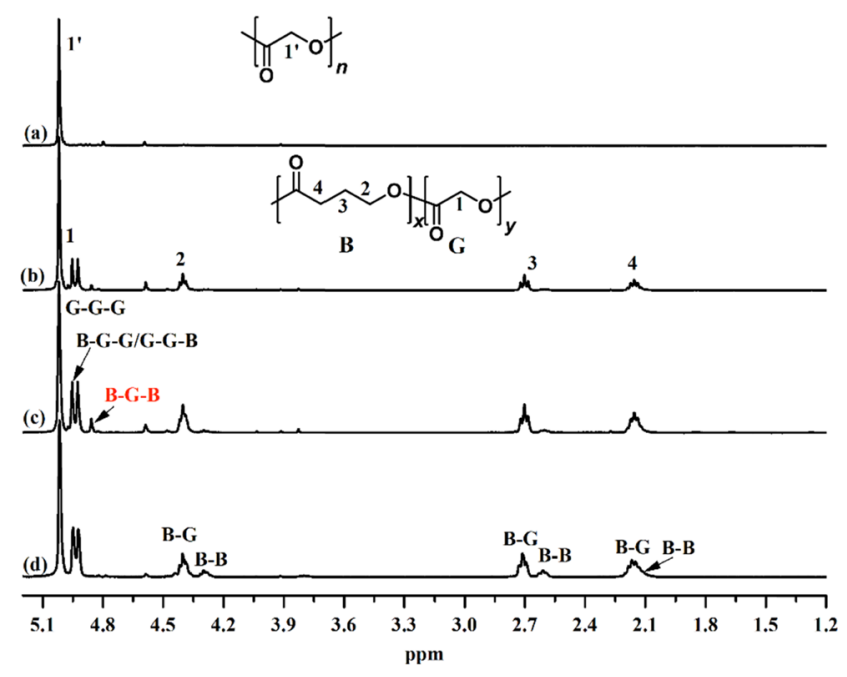

Figure 1. ${ }^{1} \mathrm{H}$ NMR spectra $\left(\mathrm{CF}_{3} \mathrm{COOD}\right)$ of poly (GA-co-BL)s: (a) BL $=0 \%$ (PGA for comparison); (b) BL $\%=14.3 \%$ (run 12, Table 1); (c) $\mathrm{BL} \%=20.0 \%$ (run 15 , Table 1 ); and (d) $\mathrm{BL} \%=20.2 \%$ (produced by ROC, run 5, Table S1).

produced by the cationic ROC is substantially different, in which the $B-G-B$ alternating sequence was not detected and the content of the $\mathrm{B}-\mathrm{B}$ homosequence was much higher (23.0\%, Figure $1 \mathrm{~d}$; entry 6, Table 2 ). Overall, the low content of the $\mathrm{B}-\mathrm{B}$ homosequence and the presence of the appreciable amount of the unique $B-G-B$ alternating (i.e., isolated $G$ ) sequence indicate that poly (GA-co-BL) formed by TEster has a much more sequence-defined structure than that formed by ROC. The observed low content of the B-B homo-sequence in the copolymer is presumably a result of a combination of two factors. First, the nucleophilic attack of the B-centered anion onto ring-opened $\mathrm{B}$ units $\left(k_{\mathrm{BB}^{\prime}}\right.$ pathway, Scheme 1$)$ is infrequent. Second, the nucleophilic attack of the B-centered anion onto the monomer B molecules ( $k_{\mathrm{BB}}$ pathway, Scheme 1 ) is strongly competed by the backbiting ring-closed degradation reaction of $\cdots \mathrm{B}-\mathrm{B}-\mathrm{B}-\mathrm{OH}$ that has a low transition state (TS) energy, as indicated by our computational study (vide infra). The same sequence structures were also observed from the ${ }^{13} \mathrm{C}$ NMR spectra (Figure S6), thus providing corroborative evidence for the microstructure assignments.

The thermal properties of poly(GA-co-BL)s with different $\mathrm{BL}$ incorporations and sequences were examined by differential scanning calorimetry and thermal gravimetric analysis (TGA). As compared to PGA, which displays a $T_{\mathrm{m}}$ of $219^{\circ} \mathrm{C}$ without a noticeable $T_{\mathrm{g}}$ due to its high crystallinity, both $T_{\mathrm{m}}$ value and crystallinity of the copolymers decreased gradually with increasing BL incorporation, coupled with an appearance of $T_{\mathrm{g}}$ transition (Figures S7 and S8), highlighting the plasticizing effect of the incorporated $\mathrm{BL}$ units in the copolymer. Noteworthy also is the observation of a single $T_{\mathrm{m}}$ for the copolymer, further confirming the homogeneous composition of the copolymer. More significantly, poly(GA-co-BL)s produced by the TEster and ROC methods exhibited largely different thermostability, in reference to that of PGA (Figure $2)$. In the case of poly (GA-co-BL) formed by $\operatorname{ROC}\left(M_{\mathrm{n} G \mathrm{CP}}=\right.$

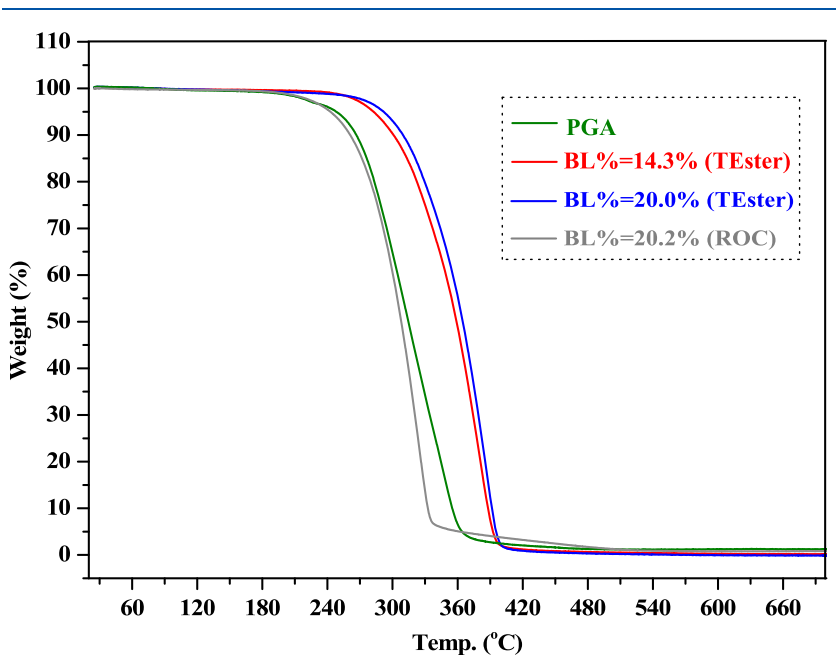

Figure 2. TGA curves: PGA (green); poly(GA-co-BL) with BL $\%=$ $14.3 \%$ produced by TEster (red); poly (GA-co-BL) with $\mathrm{BL} \%=$ $20.0 \%$ produced by TEster (blue); poly(GA-co-BL) with $\mathrm{BL} \%=$ $20.2 \%$ produced by ROC (gray).

$6.80 \mathrm{~kg} / \mathrm{mol}, 20.2 \% \mathrm{BL}$ incorporation), the $T_{\mathrm{d}}$ value is $241^{\circ} \mathrm{C}$, which is somewhat lower than that of PGA $\left(T_{\mathrm{d}}=248^{\circ} \mathrm{C}\right)$. In sharp contrast, at the very similar level of molecular weight $\left(M_{\mathrm{n} \text { GPC }}=6.61 \mathrm{~kg} / \mathrm{mol}\right)$ and $\mathrm{BL}$ incorporation $(20.0 \%)$, poly(GA-co-BL) produced by TEster has a high $T_{\mathrm{d}}$ value of $292{ }^{\circ} \mathrm{C}$, which is 51 and $44{ }^{\circ} \mathrm{C}$ higher than that of the copolymer formed by ROC and PGA, respectively.

The different thermostability between the two types of copolymers can be attributed to different monomer sequence structures, but an important fundamental question is how the copolymer sequences affect the thermostability. In principle, poly(GA-co-BL) presents three types of cleavable sites during thermal degradation, including cleavages of continuous $B-B$ and $\mathrm{G}-\mathrm{G}$ homosequences and $\mathrm{B}-\mathrm{G}$ alternating sequences. As the $T_{\mathrm{d}}$ value of PGA is higher than that of the linear PBL (208

Table 2. Molar Fractions of Different Sequence Structures Calculated by ${ }^{1} \mathrm{H}$ NMR Spectra

\begin{tabular}{|c|c|c|c|c|c|c|}
\hline \multirow[b]{2}{*}{ entry } & \multirow[b]{2}{*}{ incorp. (\%) } & \multicolumn{3}{|c|}{ glycolyl unit $(\%)^{d}$} & \multicolumn{2}{|c|}{ BL-ring-opened unit $(\%)^{d}$} \\
\hline & & $\mathrm{G}-\mathrm{G}-\mathrm{G}$ & $\mathrm{G}-\mathrm{G}-\mathrm{B} / \mathrm{B}-\mathrm{G}-\mathrm{G}$ & $B-G-B$ & $B-G$ & $\mathrm{~B}-\mathrm{B}$ \\
\hline $1^{a}$ & 5.00 & 93.5 & 5.85 & 0.65 & 92.6 & 7.40 \\
\hline $2^{a}$ & 14.3 & 73.6 & 24.6 & 1.80 & 93.5 & 6.50 \\
\hline $3^{a}$ & 18.6 & 64.4 & 32.4 & 3.20 & 92.9 & 7.10 \\
\hline $4^{a}$ & 20.0 & 60.8 & 34.7 & 4.50 & 92.9 & 7.10 \\
\hline $5^{b}$ & 16.8 & 65.4 & 31.6 & 3.00 & 93.3 & 6.70 \\
\hline $6^{c}$ & 20.2 & 60.8 & 39.2 & 0 & 77.0 & 23.0 \\
\hline
\end{tabular}

${ }^{a}$ Poly $(\mathrm{GA}-c o-\mathrm{BL})$ s produced by TEster with $[\mathrm{La}] / \mathrm{BnOH} .{ }^{b}$ Poly $(\mathrm{GA}-c o-\mathrm{BL})$ produced by TEster with TBD/BnOH. ${ }^{c}$ Poly $(\mathrm{GA}-c o-\mathrm{BL})$ produced by ROC with $\mathrm{BF}_{3} \cdot \mathrm{Et}_{2} \mathrm{O} / \mathrm{BnOH}$. ${ }^{d}$ Molar ratios of different sequence linkages determined by ${ }^{1} \mathrm{H}$ NMR spectra (see Supporting Information (SI) for details). 
${ }^{\circ} \mathrm{C}$ ) but considerably lower than that of the poly(GA-co-BL) formed by TEster that mainly consists of $G-G$ continuous and $\mathrm{B}-\mathrm{G}$ alternating sequences; it can be concluded that the thermal stability of the sequence structures follows the order of $\mathrm{B}-\mathrm{G}>\mathrm{G}-\mathrm{G}>\mathrm{B}-\mathrm{B}$. This simple analysis suggests that the more sequence-defined the structure the copolymer is, the higher the thermal stability it possesses. The copolymer formed by ROC contains a high content of $\mathrm{B}-\mathrm{B}$ continuous sequence (23.0\%) without any detectable isolated G sequence (entry 6, Table 2), while the copolymer formed by the TEster contains $4.5 \%$ of the $B-G-B$ alternating sequence and a much-reduced amount of the $B-B$ continuous sequence $(7.1 \%$, entry 4 , Table 2). Therefore, the poly(GA-co-BL) formed by TEster exhibits a much higher thermal stability than the poly (GA-co-BL) formed by ROC, thanks to the generated isolated $\mathrm{G}$ sequence and the reduced $B-B$ continuous sequence. Moreover, the $T_{d}$ value of the TEster copolymer enhances with increasing $\mathrm{BL}$ incorporation (e.g., $\mathrm{BL} \%=14.3 \%, T_{\mathrm{d}}=280{ }^{\circ} \mathrm{C} ; \mathrm{BL} \%=20.0 \%, T_{\mathrm{d}}=$ $292{ }^{\circ} \mathrm{C}$ ), which can also be explained by a more sequencedefined structure as a result of an increase of the $B-G-B$ sequence from 1.8 to $4.5 \%$.

Computational Study of Sequence/Thermostability Relationship. We also addressed this sequence/thermostability relationship through density functional theory (DFT) calculations (see the SI for computational details) performed on the transition-state (TS) energies involved in the possible decomposition pathways of the chains with various sequences (Scheme 2). Focusing first on the chains with continuous $\mathrm{G}$ and $\mathrm{B}$ sequences carrying the $-\mathrm{OH}$ end group, represented by $\cdots \mathrm{G}-\mathrm{G}-\mathrm{G}-\mathrm{OH}$ and $\cdots \mathrm{B}-\mathrm{B}-\mathrm{B}-\mathrm{OH}$, the calculated $\Delta G^{\neq}$of the 6- and 5-membered TSs accounting for the first degradation step of the PGA and PBL chains was 53.9 and $46.9 \mathrm{kcal} / \mathrm{mol}$, respectively. This result suggests that PGA is more thermally resistant, thus possessing higher thermostability than PBL, consistent with the observed $T_{\mathrm{d}}$ values: $248{ }^{\circ} \mathrm{C}$ for PGA and $208{ }^{\circ} \mathrm{C}$ for PBL. Replacing the third and second $\mathrm{G}$ unit in $\cdots \mathrm{G}-\mathrm{G}-\mathrm{G}-\mathrm{OH}$ with a $\mathrm{B}$ unit gave $\cdots \mathrm{B}-\mathrm{G}-\mathrm{G}-\mathrm{OH}$ and $\cdots \mathrm{G}-\mathrm{B}-\mathrm{G}-\mathrm{OH}$ sequences, with the calculated $\Delta G^{\neq}$values of 55.4 and $59.3 \mathrm{kcal} / \mathrm{mol}$ for their respective 6- and 8-membered degradation TS (Scheme S1). This result is intriguing, implying that the copolymer with isolated G units should be more thermally stable than both homopolymers, also consistent with the experimental observations (vide supra). Noteworthy, the sequence resulting from the replacement of both the second and third $\mathrm{G}$ units down the chain, $\cdots \mathrm{B}-\mathrm{B}-\mathrm{G}-\mathrm{OH}$, was computed to be even more resistant to degradation, with a higher $\Delta G^{\neq}$value of 61.5 $\mathrm{kcal} / \mathrm{mol}$ for the 8 -membered TS; this is a result of the interplay between the conformation of the ring-unzipping TS and the strength of the breaking/forming bonds, as the ester bond involving a B unit is stronger than the ester bond involving a $\mathrm{G}$ unit (see the SI). An alternative degradation pathway for the isolated $G$ unit located at the chain end is through a 3-membered TS, but the free energy required is the highest, with $\Delta G^{\neq}>68 \mathrm{kcal} / \mathrm{mol}$ (Scheme 2).

Likewise, substituting the $\mathrm{B}$ units in the starting chain $\cdots \mathrm{B}-$ $\mathrm{B}-\mathrm{B}-\mathrm{OH}$ with a $\mathrm{G}$ unit gave chains with sequences of $\cdots \mathrm{G}-$ $\mathrm{B}-\mathrm{B}-\mathrm{OH}, \cdots \mathrm{B}-\mathrm{G}-\mathrm{B}-\mathrm{OH}$, and $\cdots \mathrm{G}-\mathrm{G}-\mathrm{B}-\mathrm{OH}$. The effect of the third $G$ unit on the decomposition TS energy is negligible, but the second $\mathrm{G}$ unit lowered the TS further by 3.7 $\mathrm{kcal} / \mathrm{mol}$ (second vs third entry, Scheme 2) due to the breaking of the weaker $\mathrm{G}$ ester bond. As for the chain carrying a $\mathrm{B}-\mathrm{OH}$ terminal group, elimination of a $\mathrm{B}$ unit is relatively
Scheme 2. Proposed Transition States and Calculated $\Delta G^{\neq}$ (kcal/mol) Values of Degradation Pathways of the Chains with Continuous $\mathrm{G}$ or $\mathrm{B}$ and Isolated $\mathrm{G}$ Sequences Calculated as Energy Differences between the Transition State and the Corresponding Relaxed Polymer Chain

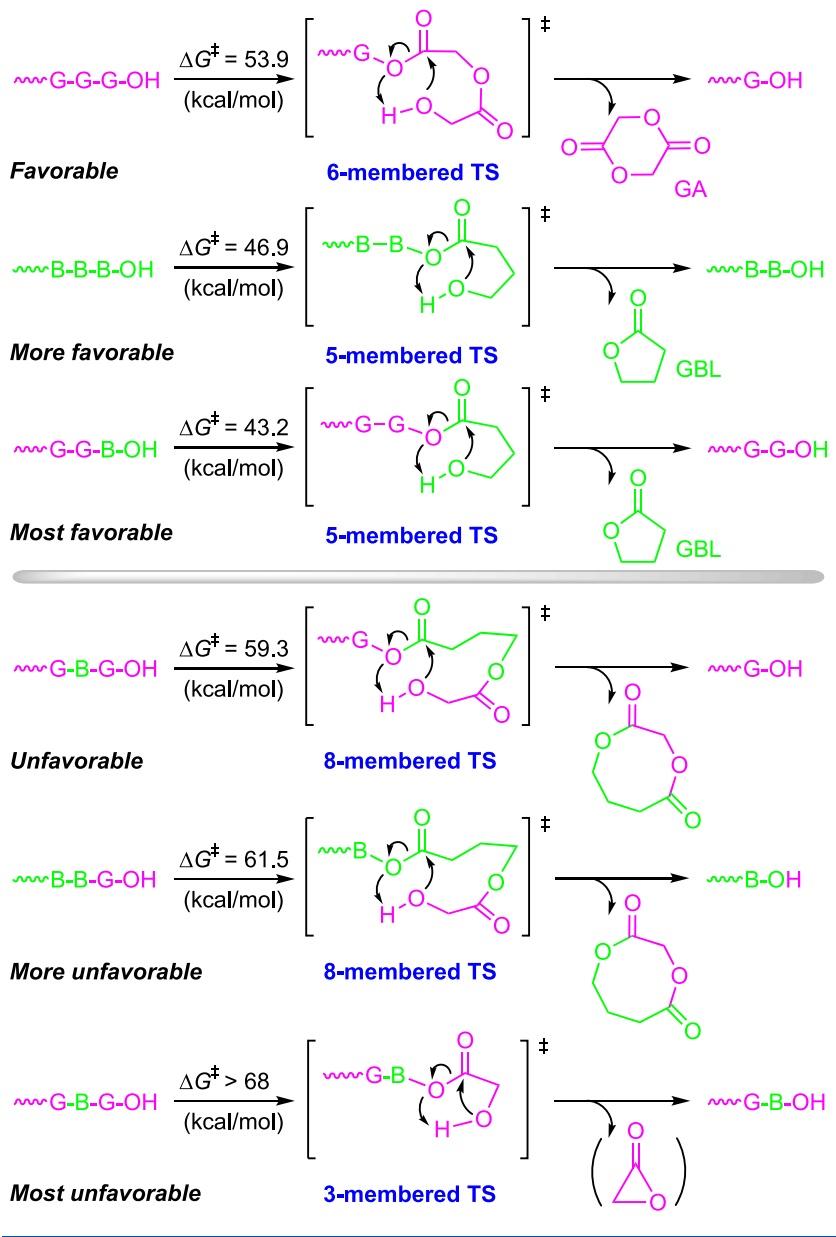

facile, until the process leads to a more stable, terminal G-OH chain. Overall, the DFT results showed that the presence of the isolated $G$ units (i.e., alternating $G / B$ sequences) along the chain and, most relevantly towards the end, or preferably placed at the chain end, renders a more difficult decomposition process, thus enhancing the thermal properties of the copolymer possessing such sequences. Worth noting here is that the TS for intrachain backbiting, modeled by $\cdots \mathrm{G}-\mathrm{G}-\mathrm{OR}$ and $\cdots \mathrm{B}-\mathrm{B}-\mathrm{OR}(\mathrm{R}=\mathrm{Me})$, has much higher $\Delta G^{\neq}$energies, about $95 \mathrm{kcal} / \mathrm{mol}$. This result agrees with the considerably higher thermostability observed for the cyclic PBL relative to its linear counterpart. ${ }^{15}$

To experimentally probe the influence of the isolated $G$ sequence on the polymer thermal stability, we introduced a $\mathrm{G}$ unit into the PBL-OH chain end, namely, PBL-COCH${ }_{2} \mathrm{OH}$, via the reaction of $\mathrm{PBL}-\mathrm{OH}$ with 2-[(tert-butyldimethylsilyl)oxy]acetyl chloride and subsequent deprotection. The successful chain-end modification was clearly shown by ${ }^{1} \mathrm{H}$ NMR analysis in combination with matrix-assisted laser desorption ionization time-of-flight mass spectrometry analysis (Figures S9 and S10). Importantly, the resultant PBL$\mathrm{COCH}_{2} \mathrm{OH}$ showed remarkably higher thermal stability $\left(T_{\mathrm{d}}\right.$ $\left.=271{ }^{\circ} \mathrm{C}\right)$ than PBL-OH $\left(T_{\mathrm{d}}=208{ }^{\circ} \mathrm{C}\right)$ (Figure S11), thereby 
Scheme 3. Chemical Recycling Route of poly(GA-co-BL)

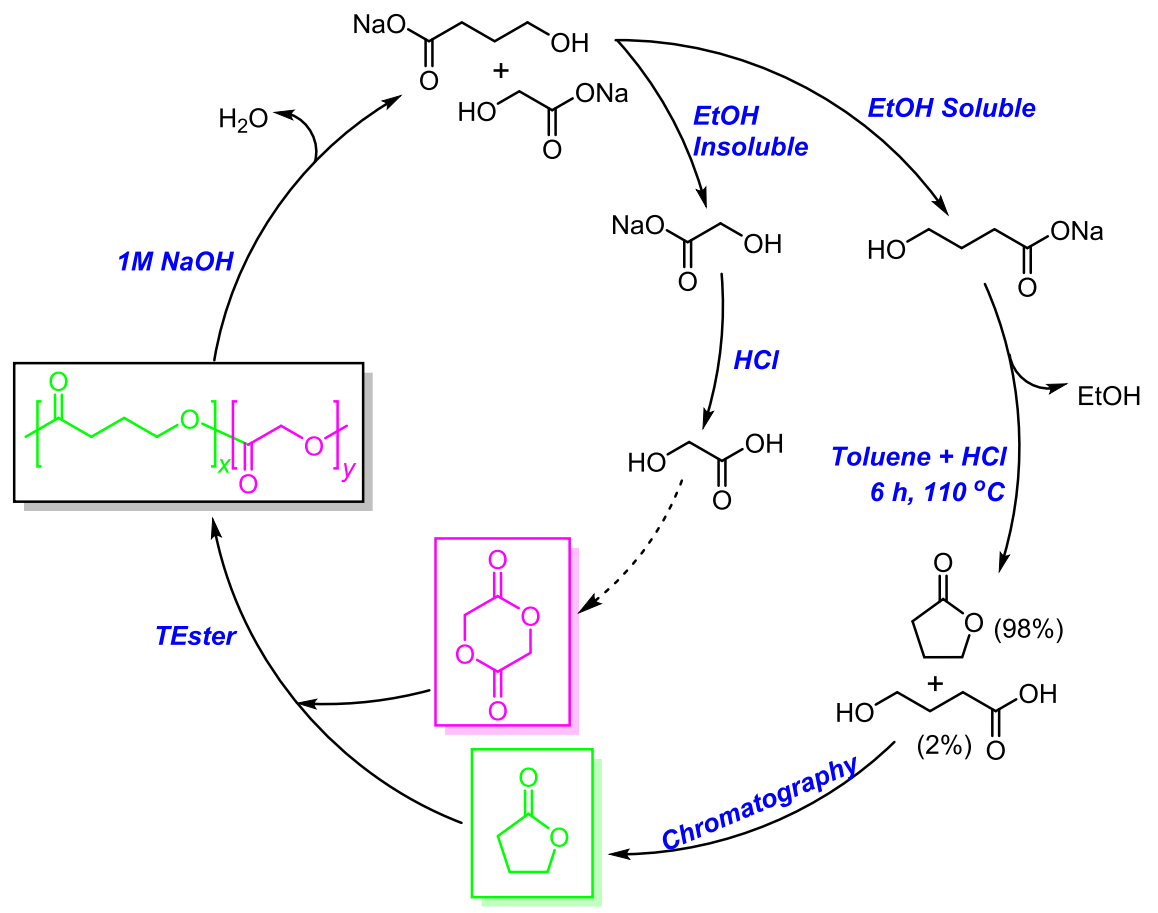

further confirming that the isolated G sequence is responsible for enhancing the thermal stability.

Chemical Recyclability of Upconverted Poly(GA-co$\mathrm{BL})$. The chemical recyclability of poly(GA-co-BL) was examined by both thermolysis at high temperature $(\sim 300$ ${ }^{\circ} \mathrm{C}, 12 \mathrm{~h}$ ) and chemolysis in the presence of a simple metal salt [e.g., $\mathrm{Bi}(\mathrm{OTf})_{3}, \mathrm{ZnCl}_{2}$ ] at milder temperature $\left(120^{\circ} \mathrm{C}, 12 \mathrm{~h}\right)$. However, neither of these approaches recycled the feedstock of the $\mathrm{G}$ units present in the copolymer, although $\mathrm{B}$ units in the copolymer can be quantitatively recovered in the form of a BL monomer (Figure S12). The desired glycolide was formed during thermolysis but was accompanied by glycolic acid and PGA oligomer, while during the chemolysis, only the formation of PGA oligomer was observed (Figure S12). To reduce the energy input and establish complete feedstock recycling, we then examined the hydrolysis pathway. Monitoring of the hydrolysis process in situ by ${ }^{1} \mathrm{H}$ NMR indicated that hydrolysis in acidic aqueous solution $\left(\left[\mathrm{H}^{+}\right] /\right.$ $\mathrm{D}_{2} \mathrm{O}=1.0 \mathrm{M}$ ) led to only a small degree of degradation (Figures S13 and S17) and a trace of degradation products was detectable under the neutral condition (Figures S14 and S17) even after 16 days. In sharp contrast, basic aqueous conditions $\left(\left[\mathrm{OH}^{-}\right] / \mathrm{D}_{2} \mathrm{O}=1.0 \mathrm{M}\right)$ significantly enhanced the rate of hydrolytic degradation; within $2 \mathrm{~h}$ degradation of the copolymer was completed (Figure S16), affording sodium glycollate and sodium $\gamma$-hydroxybutyrate as clean products (Figures S15 and S17). Based on this finding, we developed a simple and efficient recycling route to recycle the feedstocks of poly(GA-co-BL), as depicted in Scheme 3. The resulting sodium glycollate and sodium $\gamma$-hydroxybutyrate can be easily separated due to large solubility difference in ethanol, where the ethanol-soluble fraction gave sodium $\gamma$-hydroxybutyrate, while the insoluble fraction gave sodium glycollate (Figure S18). After acidification, glycolic acid, the industrial raw material of glycolide and PGA, was obtained in quantitative yield (98\%, Figure 3, top; Figure S19). The quantitative recovery of BL (98\%, Figure S20) was achieved via cyclization
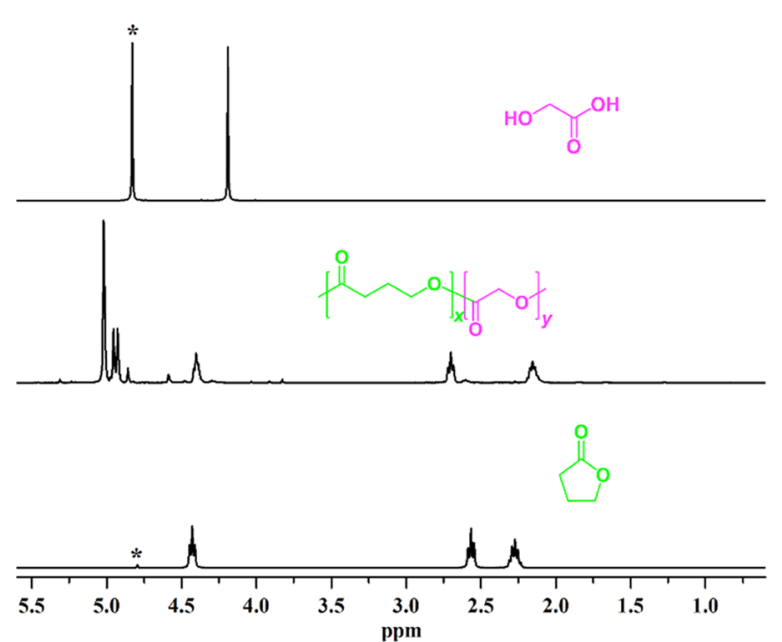

Figure 3. Overlays of ${ }^{1} \mathrm{H}$ NMR spectra: recovered glycolic acid (top, $\mathrm{D}_{2} \mathrm{O}$ ), starting poly $(\mathrm{GA}-\mathrm{co}-\mathrm{BL})$ (middle, $\mathrm{CF}_{3} \mathrm{COOD}$ ), and recovered $\mathrm{BL}$ (bottom, $\mathrm{D}_{2} \mathrm{O}$ ). $*$ The residual NMR solvent peak.

of sodium $\gamma$-hydroxybutyrate in toluene at $110{ }^{\circ} \mathrm{C}$ for $6 \mathrm{~h}$ under acidic conditions, bypassing $\gamma$-hydroxybutyric acid, which is a FDA-regulated substance and imposes potential dangers to human health if misused. After flash chromatography, pure BL was obtained in high isolated yield of $94 \%$ (Figure 3, bottom).

\section{CONCLUSIONS}

This work established the TEster as a convenient and effective method for achieving closed-loop upcycling of PGA in the industrial solvent $\mathrm{BL}$ via the formation of the copolymer bearing the property-enhancing isolated $\mathrm{G}$ sequences and full chemical recyclability. The successful example presented here has not only addressed the challenge encountered in the synthesis of poly(GA-co-BL) via coordination or anionic copolymerization of $\mathrm{GA}$ and $\mathrm{BL}$ due to their very large 
reactivity difference but, more importantly, also led to the discovery of the isolated $G$ sequence generated in the copolymer unique to the TEster approach, which is responsible for the enhanced thermal stability of the resulting copolymer. This upcycled copolymer can be fully recycled back to pure glycolic acid and BL building blocks using a simple and efficient recycling route, thus successfully constructing a closed-loop polymer upcycling scheme. Noteworthy also is the fact that this upcycling can also be performed using a mixture of homopolymers (Figures S21-S24). Future work will examine if the TEster strategy disclosed herein could also be applicable to other polyester/monomer pairs and homopolymer pairs and if advanced catalysts could be designed to enhance the TEster selectivity for generating property-enhancing sequences.

\section{ASSOCIATED CONTENT}

\section{S Supporting Information}

The Supporting Information is available free of charge on the ACS Publications website at DOI: 10.1021/acs.macromol.9b00817.

Materials, reagents, and methods; synthesis of PGA homopolymer; general transesterification procedures; polymer characterizations; chain-end modification of PBL; feedstock recycling of poly(GA-co-BL), computational details (PDF)

\section{AUTHOR INFORMATION}

\section{Corresponding Authors}

*E-mail: miaohong@sioc.ac.cn (M.H.).

*E-mail: laura.falivene@kaust.edu.sa (L.F.).

*E-mail: eugene.chen@colostate.edu (E.Y.-X.C.).

\section{ORCID}

Miao Hong: 0000-0003-1016-882X

Laura Falivene: 0000-0003-1509-6191

Luigi Cavallo: 0000-0002-1398-338X

Eugene Y.-X. Chen: 0000-0001-7512-3484

\section{Notes}

The authors declare no competing financial interest.

\section{ACKNOWLEDGMENTS}

The work done at SIOC was supported by The Thousand Talents Plan for Young Scholars of China, The Science and Technology Commission of Shanghai Municipality (No. 17JC1401200) to M.H. and the work performed at CSU was supported by the U.S. National Science Foundation (NSF1664915) to E.Y.-X.C.

\section{REFERENCES}

(1) Garcia, J. M.; Robertson, L. M. The future of plastics recycling. Science 2017, 358, 870-872.

(2) Hong, M.; Chen, E. Y.-X. Chemically recyclable polymers: a circular economy approach to sustainability. Green Chem. 2017, 19, 3692-3706.

(3) Lu, X.-B.; Liu, Y.; Zhou, H. Learning nature: recyclable monomers and polymers. Chem. - Eur. J. 2018, 24, 11255-11266.

(4) Rahimi, A.; García, J. M. Chemical recycling of waste plastics for new materials production. Nat. Rev. Chem. 2017, 1, No. 0046.

(5) Schneiderman, D. K.; Hillmyer, M. A. 50th Anniversary perspective: there is a great future in sustainable polymers. Macromolecules 2017, 50, 3733-3749.
(6) Tang, X.; Chen, E. Y.-X. Toward infinitely recyclable plastics derived from renewable cyclic esters. Chem 2019, 5, 284-312.

(7) Zhang, X.; Fevre, M.; Jones, G. O.; Waymouth, R. M. Catalysis as an enabling science for sustainable polymers. Chem. Rev. 2018, 118, 839-885.

(8) Zhu, Y.; Romain, C.; Williams, C. K. Sustainable polymers from renewable resources. Nature 2016, 540, 354-362.

(9) Garcia, J. M.; Jones, G. O.; Virwani, K.; McCloskey, B. D.; Boday, D. J.; ter Huurne, G. M.; Horn, H. W.; Coady, D. J.; Bintaleb, A. M.; Alabdulrahman, A. M. S.; Alsewailem, F.; Almegren, H. A. A.; Hedrick, J. L. Recyclable, strong thermosets and organogels via paraformaldehyde condensation with diamines. Science 2014, 344, $732-735$.

(10) Liu, Y.; Zhou, H.; Guo, J.-Z.; Ren, W.-M.; Lu, X.-B. Completely recyclable monomers and polycarbonate: approach to sustainable polymers. Angew. Chem., Int. Ed. 2017, 56, 4862-4866.

(11) Lizundia, E.; Makwana, V. A.; Larrañaga, A.; Vilas, J. L.; Shaver, M. P. Thermal, structural and degradation properties of an aromaticaliphatic polyester built through ring-opening polymerisation. Polym. Chem. 2017, 8, 3530-3538.

(12) MacDonald, J. P.; Shaver, M. P. An aromatic/aliphatic polyester prepared via ring-opening polymerisation and its remarkably selective and cyclable depolymerisation to monomer. Polym. Chem. 2016, 7, 553-559.

(13) Schneiderman, D. K.; Vanderlaan, M. E.; Mannion, A. M.; Panthani, T. R.; Batiste, D. C.; Wang, J. Z.; Bates, F. S.; Macosko, C. W.; Hillmyer, M. A. Chemically recyclable biobased polyurethanes. ACS Macro. Lett. 2016, 5, 515-518.

(14) Xiong, M.; Schneiderman, D. K.; Bates, F. S.; Hillmyer, M. A.; Zhang, K. Scalable production of mechanically tunable block polymers from sugar. Proc. Natl. Acad. Sci. U.S.A. 2014, 111, 83578362.

(15) Hong, M.; Chen, E. Y.-X. Completely recyclable biopolymers with linear and cyclic topologies via ring-opening polymerization of gamma-butyrolactone. Nat. Chem. 2016, 8, 42-49.

(16) Hong, M.; Chen, E. Y.-X. Towards truly sustainable polymers: a metal-free recyclable polyester from biorenewable non-strained gamma-butyrolactone. Angew. Chem., Int. Ed. 2016, 55, 4188-4193.

(17) Tang, X.; Hong, M.; Falivene, L.; Caporaso, L.; Cavallo, L.; Chen, E. Y.-X. The quest for converting biorenewable bifunctional alpha-methylene-gamma-butyrolactone into degradable and recyclable polyester: controlling vinyl-addition/ring-opening/cross-linking pathways. J. Am. Chem. Soc. 2016, 138, 14326-14337.

(18) Zhu, J.-B.; Watson, M. E.; Tang, J.; Chen, E. Y.-X. A synthetic polymer system with repeatable chemical recyclability. Science 2018, 360, 398-403.

(19) Zhu, J.-B.; Chen, E. Y.-X. Living coordination polymerization of a six-five bicyclic lactone to produce completely recyclable polyester. Angew. Chem., Int. Ed. 2018, 57, 12558-12562.

(20) Zhu, J.-B.; Chen, E. Y.-X. Catalyst-sidearm-induced stereoselectivity switching in polymerization of a racemic lactone for stereocomplexed crystalline polymer with a circular life cycle. Angew. Chem., Int. Ed. 2019, 58, 1178-1182.

(21) Jehanno, C.; Pérez-Madrigal, M.; Demarteau, J.; Sardon, H.; Dove, A. P. Organocatalysis for depolymerisation. Polym. Chem. 2019, 10, $172-186$.

(22) Eagan, J. M.; Xu, J.; Girolamo, R. D.; Thurber, C. M.; Macosko, C. W.; LaPointe, A. M.; Bates, F. S.; Coates, G. W. Combining polyethylene and polypropylene: Enhanced performance with PE/iPP multiblock polymers. Science 2017, 355, 814-816.

(23) Easterling, C. P.; Kubo, T.; Orr, Z. M.; Fanucci, G. E.; Sumerlin, B. S. Synthetic upcycling of polyacrylates through organocatalyzed post-polymerization modification. Chem. Sci. 2017, 8, 7705-7709.

(24) Fahnhorst, G. W.; Hoye, T. R. A carbomethoxylated polyvalerolactone from malic acid: synthesis and divergent chemical recycling. ACS Macro Lett. 2018, 7, 143-147.

(25) Gardea, F.; Garcia, J. M.; Boday, D. J.; Bajjuri, K. M.; Naraghi, M.; Hedrick, J. L. Hybrid poly(aryl ether sulfone amide)s for 
advanced thermoplastic composites. Macromol. Chem. Phys. 2014, 215, 2260-2267.

(26) Jia, X.; Qin, C.; Friedberger, T.; Guan, Z.; Huang, Z. Efficient and selective degradation of polyethylenes into liquid fuels and waxes under mild conditions. Sci. Adv. 2016, 2, No. e1501591.

(27) Jones, G. O.; Yuen, A.; Wojtecki, R. J.; Hedrick, J. L.; García, J. M. Computational and experimental investigations of one-step conversion of poly(carbonate)s into value-added poly(aryl ether sulfone)s. Proc. Natl. Acad. Sci. U.S.A. 2016, 113, 7722-7726.

(28) Kenny, S. T.; Runic, J. N.; Kaminsky, W.; Woods, T.; Babu, R. P.; Keely, C. M.; Blau, W.; O'Connor, K. E. Up-cycling of PET (polyethylene terephthalate) to the biodegradable plastic PHA (polyhydroxyalkanoate). Environ. Sci. Technol. 2008, 42, 7696-7701.

(29) Rorrer, N. A.; Nicholson, S.; Carpenter, A.; Biddy, M. J.; Grundl, N. J.; Beckham, G. T. Combining reclaimed PET with biobased monomers enables plastics upcycling. Joule 2019, 1006.

(30) Austin, H. P.; Allen, M. D.; Donohoe, B. S.; Rorrer, N. A.; Kearns, F. L.; Silveira, R. L.; Pollard, B. C.; Dominick, G.; Duman, R.; Omari, K. E.; Mykhaylyk, V.; Wagner, A.; Michener, W. E.; Amore, A.; Skaf, M. S.; Crowley, M. F.; Thorne, A. W.; Johnson, C. W.; Woodcock, H. L.; McGeehan, J. E.; Beckham, G. T. Characterization and engineering of a plastic-degrading aromatic polyesterase. Proc. Natl. Acad. Sci. U.S.A. 2018, 115, E4350-E4357.

(31) Longo, J. M.; Sanford, M. J.; Coates, G. W. Ring-opening copolymerization of epoxides and cyclic anhydrides with discrete metal complexes: structure-property relationships. Chem. Rev. 2016, 116, 15167-15197.

(32) Lu, X.-B.; Ren, W.-M.; Wu, G.-P. $\mathrm{CO}_{2}$ copolymers from epoxides: catalyst activity, product selectivity, and stereochemistry control. Acc. Chem. Res. 2012, 45, 1721-1735.

(33) Wilson, J. A.; Hopkins, S. A.; Wright, P. M.; Dove, A. P. Synthesis of $\omega$-pentadecalactone copolymers with independently tunable thermal and degradation behavior. Macromolecules 2015, 48, 950-958.

(34) Xu, Y.-C.; Ren, W.-M.; Zhou, H.; Gu, G.-G.; Lu, X.-B. Functionalized polyesters with tunable degradability prepared by controlled ring-opening (co)polymerization of lactones. Macromolecules 2017, 50, 3131-3142.

(35) Wilson, J. A.; Hopkins, S. A.; Wright, P. M.; Dove, A. P. Dependence of copolymer sequencing based on lactone ring size and $\varepsilon$-substitution. ACS Macro. Lett. 2016, 5, 346-350.

(36) Badi, N.; Lutz, J. F. Sequence control in polymer synthesis. Chem. Soc. Rev. 2009, 38, 3383-3390.

(37) Lutz, J. F.; Ouchi, M.; Liu, D. R.; Sawamoto, M. Sequencecontrolled polymers. Science 2013, 341, No. 1238149.

(38) Satoh, K.; Matsuda, M.; Nagai, K.; Kamigaito, M. AABSequence living radical chain copolymerization of naturally occurring limonene with maleimide: an end-to-end sequence-regulated copolymer. J. Am. Chem. Soc. 2010, 132, 10003-10005.

(39) Huang, Z.; Noble, B. B.; Corrigan, N.; Chu, Y.; Satoh, K.; Thomas, D. S.; Hawker, C. J.; Moad, G.; Kamigaito, M.; Coote, M. L.; Boyer, C.; Xu, J. Discrete and stereospecific oligomers prepared by sequential and alternating single unit monomer insertion. J. Am. Chem. Soc. 2018, 140, 13392-13406.

(40) Ji, H.-Y.; Wang, B.; Pan, L.; Li, Y.-S. One-step access to sequence-controlled block copolymers by self-switchable organocatalytic multicomponent polymerization. Angew. Chem., Int. Ed. 2018, 57, 16888-16892.

(41) Lin, F.; Wang, M.; Pan, Y.; Tang, T.; Cui, D.; Liu, B. Sequence and regularity controlled coordination copolymerization of butadiene and styrene: strategy and mechanism. Macromolecules 2017, 50, 849856.

(42) Liu, B.; Cui, D.; Tang, T. Stereo- and temporally controlled coordination polymerization triggered by alternating addition of a Lewis acid and base. Angew. Chem., Int. Ed. 2016, 55, 11975-11978.

(43) Liu, X.; Hua, X.; Cui, D. Copolymerization of lactide and cyclic carbonate via highly stereoselective catalysts to modulate copolymer sequences. Macromolecules 2018, 51, 930-937.
(44) Liu, D.; Wang, M.; Wang, Z.; Wu, C.; Pan, Y.; Cui, D. Stereoselective copolymerization of unprotected polar and nonpolar styrenes by an yttrium precursor: control of polar-group distribution and mechanism. Angew. Chem., Int. Ed. 2017, 56, 2714-2719.

(45) Childers, M. I.; Longo, J. M.; Van Zee, N. J.; LaPointe, A. M.; Coates, G. W. Stereoselective epoxide polymerization and copolymerization. Chem. Rev. 2014, 114, 8129-8152.

(46) Dechy-Cabaret, O.; Martin-Vaca, B.; Bourissou, D. Controlled ring-opening polymerization of lactide and glycolide. Chem. Rev. 2004, 104, 6147-6176.

(47) Vert, M. Polyglycolide and Copolyesters with Lactide. Biopolymers-Polyesters III: Applications and Commercial Products; Steinbuchel, A., Doi, Y., Eds.; Wiley-VCH: Weinheim, 2002.

(48) Li, J.; Stayshich, R. M.; Meyer, T. Y. Exploiting sequence to control the hydrolysis behavior of biodegradable PLGA copolymers. J. Am. Chem. Soc. 2011, 133, 6910-6913.

(49) Stayshich, R. M.; Meyer, Y. T. New insights into poly(lactic-coglycolic acid) microstructure: using repeating sequence copolymers to decipher complex NMR and thermal behavior. J. Am. Chem. Soc. 2010, 132, 10920-10934.

(50) Washington, M. A.; Swiner, D. J.; Bell, K. R.; Fedorchak, M. V.; Little, S. R.; Meyer, T. Y. The impact of monomer sequence and stereochemistry on the swelling and erosion of biodegradable poly(lactic-co-glycolic acid) matrices. Biomaterials 2017, 117, 66-76.

(51) Weiss, R. M.; Jones, E. M.; Shafer, D. E.; Stayshich, R. M.; Meyer, T. Y. Synthesis of repeating sequence copolymers of lactic, glycolic, and caprolactic acids. J. Polym. Sci., Part A: Polym. Chem. 2011, 49, 1847-1855.

(52) Weiss, R. M.; Li, J.; Liu, H. H.; Washington, M. A.; Giesen, J. A.; Grayson, S. M.; Meyer, T. Y. Determining sequence fidelity in repeating sequence poly(lactic-co-glycolic acid)s. Macromolecules 2017, 50, 550-560.

(53) Meduri, A.; Fuoco, T.; Lamberti, M.; Pellecchia, C.; Pappalardo, D. Versatile copolymerization of glycolide and rac-lactide by dimethyl(salicylaldiminato)aluminum compounds. Macromolecules 2014, 47, 534-543.

(54) Qian, H.; Wohl, A. R.; Crow, J. T.; Macosko, C. W.; Hoye, T. R. A strategy for control of "random" copolymerization of lactide and glycolide: application to synthesis of PEG-b-PLGA block polymers having narrow dispersity. Macromolecules 2011, 44, 7132-7140.

(55) Bomgardner, M. M. Biobased Polymers. Chem. Eng. News Arch. 2014, 92, 10-14.

(56) Zhao, N.; Ren, C.; Li, H.; Li, Y.; Liu, S.; Li, Z. Selective ringopening polymerization of non-strained gamma-butyrolactone catalyzed by a cyclic trimeric phosphazene base. Angew. Chem., Int. Ed. 2017, 56, 12987-12990.

(57) Lin, L.; Han, D.; Qin, J.; Wang, S.; Xiao, M.; Sun, L.; Meng, Y. Nonstrained $\gamma$-butyrolactone to high-molecular-weight $\operatorname{poly}(\gamma$-butyrolactone): facile bulk polymerization using economical ureas/ alkoxides. Macromolecules 2018, 51, 9317-9322.

(58) Zhang, C.-J.; Hu, L.-F.; Wu, H.-L.; Cao, X.-H.; Zhang, X.-H. Dual organocatalysts for highly active and selective synthesis of linear poly $(\gamma$-butyrolactone)s with high molecular weights. Macromolecules 2018, 51, 8705-8711.

(59) Shen, Y.; Zhao, Z.; Li, Y.; Liu, S.; Liu, F.; Li, Z. A facile method to prepare high molecular weight bio-renewable $\operatorname{poly}(\gamma$-butyrolactone) using a strong base/urea binary synergistic catalytic system. Polym. Chem. 2019, 10, 1231-1237.

(60) Walther, P.; Frey, W.; Naumann, S. Polarized olefins as enabling (co)catalysts for the polymerization of $\gamma$-butyrolactone. Polym. Chem. 2018, 9, 3674-3683.

(61) Kricheldorf, H. R.; Mang, T.; Jonté, J. M. Polylactones, 2 copolymerization of glycolide with $\beta$-propiolactone, $\gamma$-butyrolactone or $\delta$-valerolactone. Makromol. Chem. 1985, 186, 955-976.

(62) Nakayama, A.; Kawasaki, N.; Aiba, S.; Maeda, Y.; Arvanitoyannis, I.; Yamamoto, N. Synthesis and biodegradability of novel copolyesters containing $\gamma$-butyrolactone units. Polymer 1998, $39,1213-1222$. 
(63) Hong, M.; Tang, X.; Newell, B. S.; Chen, E. Y.-X. "Nonstrained" $\gamma$-butyrolactone-based copolyesters: copolymerization characteristics and composition-dependent (thermal, eutectic, cocrystallization, and degradation) properties. Macromolecules 2017, 50, $8469-8479$.

(64) Walther, P.; Naumann, S. N-Heterocyclic olefin-based (co)polymerization of a challenging monomer: homopolymerization of $\omega$-pentadecalactone and its copolymers with $\gamma$-butyrolactone, $\delta$ valerolactone, and $\varepsilon$-caprolactone. Macromolecules 2017, 50, 84068416.

(65) Amgoune, A.; Thomas, C. M.; Ilinca, S.; Roisnel, T.; Carpentier, J.-F. Highly active, productive, and syndiospecific yttrium initiators for the polymerization of racemic beta-butyrolactone. Angew. Chem., Int. Ed. 2006, 45, 2782-2784.

(66) Kamber, N. E.; Jeong, W.; Waymouth, R. M.; Pratt, R. C.; Lohmeijer, B. G. G.; Hedrick, J. L. Organocatalytic ring-opening polymerization. Chem. Rev. 2007, 107, 5813-5840.

(67) Kiesewetter, M. K.; Shin, E. J.; Hedrick, J. L.; Waymouth, R. M. Organocatalysis: opportunities and challenges for polymer synthesis. Macromolecules 2010, 43, 2093-2107.

(68) Dove, A. P. Organic catalysis for ring-opening polymerization. ACS Macro Lett. 2012, 1, 1409-1412. 